\title{
Effects of Mental-Skills Training On the Performance of Table- Tennis Players of National Institute for Sport, Lagos.
}

\author{
Mayowa Adeyeye, Ph.D ${ }^{1}$, Haastrup Edward, Ph.D ${ }^{2}$, Adeyemo Kehinde, M.Sc ${ }^{3}$, \\ Fasoranti Afolabi B.Sc ${ }^{4}$ \\ ${ }^{1-4}$ Department of Human Kinetics and Health Education University of Lagos, Nigeria.
}

\begin{abstract}
The study examined the effects of a six-week mental-skills training programme on the performance of table-tennis players of National Institute for Sport Lagos. The sample used for this study was four $(n=4)$ higher diploma students who were offering table-tennis as part of the requirement for the award of higher diploma in coaching of the institute. They were made up of two males $(n=2)$ and two females $(n=2)$. The participants were exposed to training in three different psychological skills: goal setting, self-talk, and visualization. Program effectiveness was evaluated through two different measures, anxiety and performance. The mentalskills measures consisted of pre and post results on the Test of Performance Strategies (TOPS) and the Sport Competition Anxiety Test (SCAT-A). The performance measures consisted of the athletes recorded scores for each meet, and the questionnaire. Data collected were subjected to descriptive statistical tools of Mean Measure of dispersion, Standard deviation, as well as Pearson Moment Correlation, and T-test Inferential Statistics at significance level of 0.05 The results revealed that the majority of table-tennis players under the study had an increase in each of the mental-skills as well as the anxiety measures and overall performance.
\end{abstract}

Key Words: Mental-Skills, Goal-Setting, Positive Self-Talk, Visualization, Confidence.

\section{Introduction}

Among the various sports scientists who are involved in the preparation of athletes for competitions, the sports psychologist have always attributed the successful performance or otherwise of athletes to many factors. The ability of elite athletes to harmonize the various factors to their advantage is a major concern to the field of sport psychology. The utilization of mental preparation strategies among elite athletes have long been seen to be effective in confronting negative factors that sometimes inhibits their performance. Although in Nigeria the practice of sports psychology as a major contribution to the success of sport, men and women have so far been limited to the classrooms where sports psychology is being offered as academic programme in the university, little or no attempt have been made by stakeholders to include the services of sports psychologist in the training of Nigeria sports men especially in table tennis a sport that utilizes a minimal equipments and space when compared to other sport. Yet, for over decades, the same set of players have always dominate and represent the country in all its major national and international competitions. A country of over one hundred and fifty million people should not have taken over from these retiring players.

It is a known facts from literature that if young athletes are psychologically prepared they would easily taken over when the old players are retrieved. Research literature have identified a number of benefits with mental skills training while preparing athletes for competition and improving their quality of life. Mental preparation is the cognitive rehearsal of a physical skill without movement (Jacobs, 2002). The best practice to performance is through mental preparation. Mental preparation is the segment of sports psychology that concentrates specifically on helping athletes break through the barriers that are keeping them from performing optimally. Many athletes and coaches resist mental training because they do not understand how it can help them. In order for athletes to get the most out of their sport, it is crucial to understand the value of improving their mental game (Parker, 2000). Athletes are more likely to embrace mental training when they understand it and its benefits. However, the best way for athletes to embrace mental training is when they actually experience its power firsthand. Mental preparation is about improving ones attitude and mental skills to help perform at best by identifying limiting beliefs and embracing a healthier philosophy about one's sport. Mental skills, just like physical skills, take repetition, practice, and game-time application to develop. Helping athletes and coaches understand the mental barriers to excellent performance and the benefits of sports psychology intervention is a critical step in the mental training process. Athletes can overcome these barriers through sport psychology intervention that aim to enhance confidence, focus, composure, trust and mental preparation.

The mind directs our actions, i.e. thoughts precede actions. To deftly handle performance barriers, mental preparation is the key. When you talk about a warm-up before a game or before an exercise routine/practice session, it no longer means just a physical warm-up. Warming up has to involve the athletes thought processes, mindset and emotional state of mind. Mental-skills training is designed to work with athletes to improve their performance through cognitive strategies. Research literatures have identified a number of 
benefits with mental-skills training while preparing athletes for competitions and improving their quality of life. Among these are; improving focus (Orlick \& Partington, 1988), managing anxiety (Mamassis \& Doganis, 2004), managing emotions (Lazarus, 2000), dealing with pressure (Beilock, Afremow, Rabe, \& Carr, 2001), building confidence (Myers, Payment, \& Feltz, 2004), communicating with coaches (Sullivan, 1993), communicating with teammates (Yukelson, 1997), performing well in competition as in practice (Frey, Laguna, \& Ravizza, 2003), dealing with injury and rehabilitation (Wiese \& Weiss, 1987), dealing with personal issues (Papacharisis, Goudas, Danish, \& Theodorakis, 2005), preventing burnout (Gould, Tuffey, Udry, \& Loehr, 1996), and increasing the enjoyment of sport participation (Scanlan, Stein, \& Ravizza, 1989).

The purpose of this study therefore was to determine the effects of a six-week mental skills training programme on the performance of table tennis players of National Institute for Sports Lagos.

\section{Methodology}

The study was conducted using four students who are specializing in table-tennis in National Institute of sport located in National stadium Surulere Lagos Nigeria. The subject sampled consisted of two males $(\mathrm{n}=2)$ and two females $(\mathrm{n}=2)$ who were running a coaching degree programme, they were selected using a purposive sampling technique. The demographic data revealed that the ages of the participants ranged from 29-45 years (m $=42.1$ years, $\mathrm{SD}=6.3$ years). All of the participants were of good health status as indicated by the required physical fitness all athletes needed to obtain before being allowed to participate in a sport. For the study, athletes were required to participate in both practices and competitions. Therefore, athletes who were physically challenged or who had injuries that prevented them from practicing were excluded from the sample. The athletes that participated in the study responded to an invitation to participate in a mental-skills training program through the Head of Course. Informed consent was obtained from all the participants after filling the consent form. The research took place at the conference hall of the institute as well as an indoor training facility of the institute. Meetings for educational phase of mental-skills training took place after their scheduled practice times. The study began at the middle of the semester and lasted for six weeks. All the four participants completed Test of Performance Strategy (TOPS) and Sport Competitive Anxiety Test (SCAT-A) described below at the first meeting for the mental-skills training. The information gathered from the tests was used as baseline data. The participants also completed the performance measure at the start of the mental skills training session that was used as baseline data as well as their previous meet results.

Test of Performance Strategies (TOPS) is a questionnaire that is a self-report instrument designed to measure specific mental skills used by athletes during practice and competition (Thomas et al., 1999). It consists of eight subscales in the practice portion and eight in the competition portion. Within each of the16 subscales, there are four items resulting in a total of 112 items. The maximum score on each section (practice and competition) of the TOPS is 160 (Frey et al., 2003). A higher score indicates a greater use of mental-skills use. This measure was administered to all study participants at the beginning and end of the mental-skills training program.

The Sport Competition Anxiety Test (SCAT-A) is a self-report measure of competitive trait anxiety that has been widely used in sport psychology research. The SCAT-A was administered before the mental-skills training began was used as baseline data; it was also administered at the end of the mental-skills training program.

Using the Mamassis and Doganis (2004) study as a guide, the mental-skills training consisted of three different psychological skills: goal setting, positive self-talk, and visualization. The study consisted of one 30minute session every week for the group as a whole, the first one being an introductory session, emphasizing the importance of mental-skills in table-tennis. Each of the psychological skills outlined above were presented over a two weeks period covering a total of six weeks for the intervention program. A typical session started off with written basic information for the mental-skill that was being taught, how it would help the athletes as well as how it could be implemented into practice and competition, questions, and finally implementation of the mental exercises for that session. The data collected were subjected to descriptive statistical tools of Mean Measure of dispersion, Standard deviation, as well as Pearson Moment Correlation, and T-test Inferential Statistics at 0.05 level of significance.

\section{Findings}

The results revealed that the majority of table-tennis players under the study had an increase in each of the mental-skills as well as the anxiety measures and overall performance. The skills looked at were goal setting, self-talk, visualization and confidence. 


\section{Data analysis of the respondents are shown below;}

Table 1: Descriptive statistics of cross tabulation of goal setting for pre-test and post-test

\begin{tabular}{llllll}
\multirow{4}{*}{ Goal setting } & & $\mathbf{N}$ & Mean & Std. Deviation \\
\cline { 2 - 5 } & pre-test & 4 & 2.6250 & .61914 \\
& post-test & 4 & 2.6875 & .60208 \\
\hline
\end{tabular}

At the end of the data analysis section, it was observed that the 4 athletes had a pre-test average score of 2.63 with standard deviation of 0.62 on concentration while that of post-test has a mean value of 2.69 with standard deviation of 0.60 . In order to ascertain whether or not the difference that is observed in the groups can be attributed to the treatment, the independent t-test was carried out and the result of the analysis is shown in the table below;

Table 2: t-test of difference between the pre-test and post-test on goal-setting Independent Sample Test

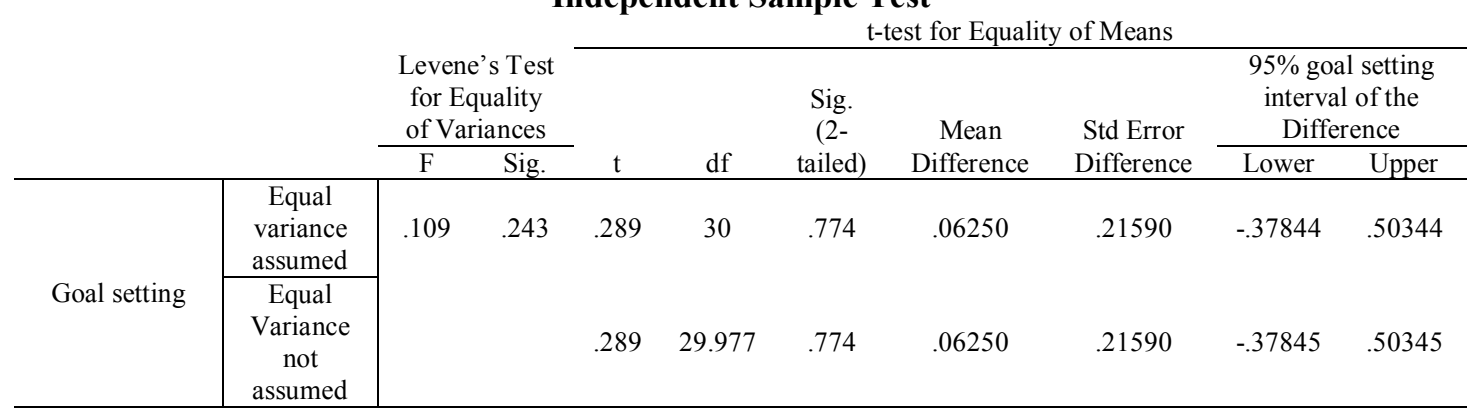

The decision rule states that the null hypothesis should be accepted when the p-value is greater than the level of significance which is 0.05 while the alternative hypothesis should be accepted when the p-value is less than the level of significance of the analysis. In this case, the p-value (Sig.) is 0.243 which is lesser than the level of significance of 0.05 ; This revealed that the four players had an increase in goal setting as well as confidence and overall performance.

Table 3: Descriptive statistics for pre-test and post-test for positive self talk

\begin{tabular}{l|llccc} 
& & Group & N & Mean & Std. Deviation \\
\cline { 2 - 5 } Self talk & pre-test & 4 & 2.6875 & .47871 \\
& post-test & 4 & 3.0000 & .00000 \\
\hline
\end{tabular}

Evidenced from the above table, the average level of positive self talk in pre-test is 2.69 with standard deviation of 0.48 while for the post-test, the average score was 3.00 with standard deviation of 0.00 . Hence the data was subjected to the t-test for verification of source of difference. The result of the analysis is presented below;

Table 4: t-test for difference in positive self talk between the pre-test and post-test Independent Samples Test

\begin{tabular}{|c|c|c|c|c|c|c|c|c|c|c|}
\hline & & \multicolumn{2}{|c|}{$\begin{array}{c}\text { Levene's Test for } \\
\text { Equality of } \\
\text { Variances }\end{array}$} & \multirow[b]{2}{*}{$\mathrm{t}$} & \multirow[b]{2}{*}{ Df } & \multirow{2}{*}{$\begin{array}{l}\text { Sig. (2- } \\
\text { tailed) }\end{array}$} & \multirow{2}{*}{$\begin{array}{c}\text { Mean } \\
\text { Difference }\end{array}$} & \multirow{2}{*}{$\begin{array}{l}\text { Std Error } \\
\text { Difference }\end{array}$} & \multicolumn{2}{|c|}{$\begin{array}{l}95 \% \text { Confidence } \\
\text { interval of the } \\
\text { Difference }\end{array}$} \\
\hline & & $\mathrm{F}$ & Sig. & & & & & & Lower & Upper \\
\hline \multirow{2}{*}{$\begin{array}{l}\text { Self } \\
\text { talk }\end{array}$} & $\begin{array}{c}\text { Equal variance } \\
\text { assumed }\end{array}$ & \multirow[t]{2}{*}{91.667} & \multirow[t]{2}{*}{.000} & $\begin{array}{c}- \\
2.611\end{array}$ & 30 & .014 & -.31250 & .11968 & -.55692 & -.06808 \\
\hline & $\begin{array}{c}\text { Equal Variance } \\
\text { not assumed }\end{array}$ & & & $\begin{array}{c}- \\
2.611\end{array}$ & 15.000 & .020 & -.31250 & .11968 & -.56759 & -.05741 \\
\hline
\end{tabular}

Since the p-value for the analysis is 0.000 which is less than the level of significance at which the test was carried out, this revealed that the four players had an increase in self-talk as well as confidence and overall performance. 
Table 5: Descriptive statistics for visualization of pre-test and post-test

\begin{tabular}{c|lllcc}
\multicolumn{1}{c}{} & Group & N & Mean & Std. Deviation \\
\cline { 2 - 6 } Visualization & pre-test & 4 & 2.4375 & .51235 \\
& post-test & 4 & 2.6875 & .47871 \\
\hline
\end{tabular}

At the end of the analysis, it was observed that the mean value for the visualization exhibited during pre-test is 2.44 with standard deviation of 0.51 while the average level of visualization exhibited during post-test is 2.69 with standard deviation of 0.48 . In order to ascertain whether or not the difference in the mean value can be attributed to the treatment, the t-test was carried out. The result is summarized in the table below;

Table 6: t-test for difference in self control in the control and experimental group Independent Samples Test

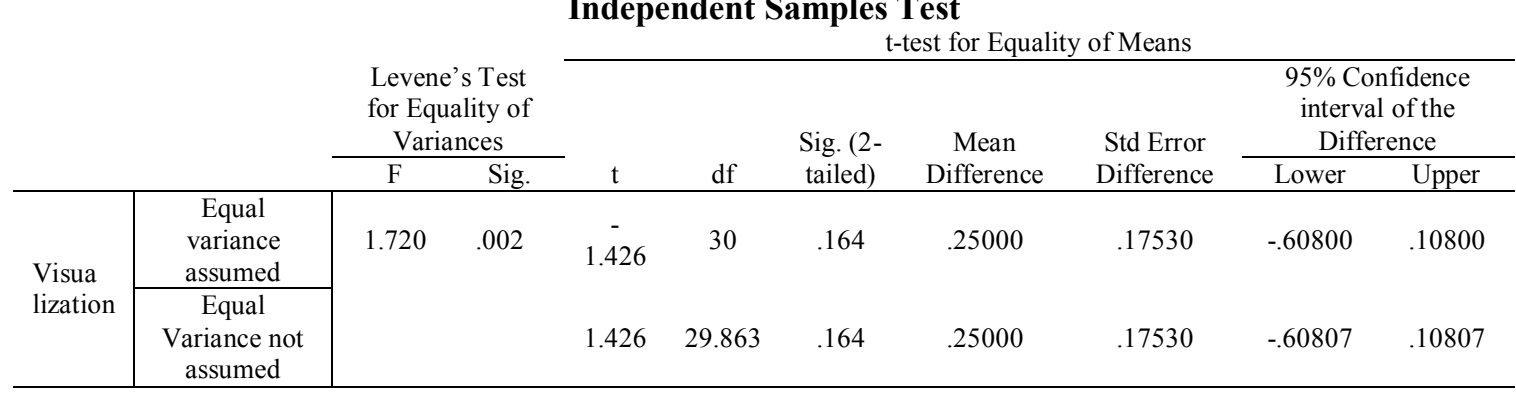

At the end of the t-test, it was observed that the p-value (0.002) is less than the level of significance at which the test was carried out; this revealed that the four players had an increase in visualization as well as confidence and overall performance.

Table 7: Descriptive statistics of confidence level in the pre-test and post-test

\begin{tabular}{lllccc}
\multicolumn{1}{c}{} & Group & N & Mean & Std. Deviation \\
\cline { 2 - 5 } Confidence & Pre-test & 4 & 2.3750 & .71880 \\
& Post-test & 4 & 3.0625 & .57373 \\
\hline
\end{tabular}

The average score for the pre-test in terms of confidence is 2.37 with standard deviation of 0.72 while that of the post-test is 3.06 with standard deviation of 0.57 . The data was subjected to the t-test to verify whether or not the difference is due to the presence of the treatment administered by the researcher. The result of the test is shown below;

Table 8: t-test of the difference in confidence level of pre-test and post-test Independent Samples Test

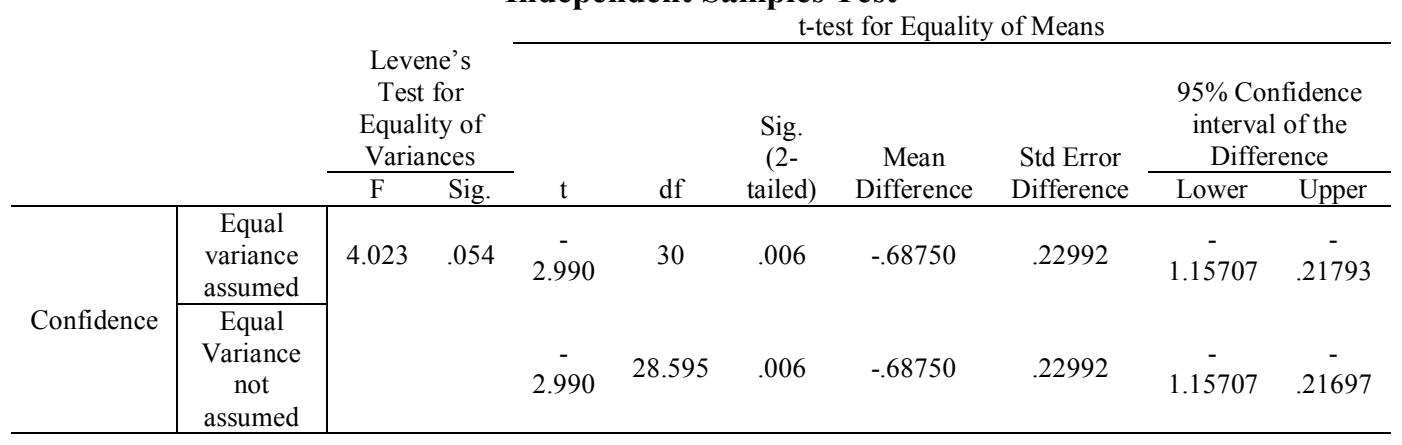

The p-value (0.054) is greater than the level of significance for the analysis, this revealed that the four players had an increase in confidence as well as overall performance.

\section{Discussion of Findings}

The purpose of this study was to find out the effect of mental skills such as goal-setting, self-talk, and visualisation on confidence and overall performance of table-tennis players of National Institutes of Sport. Many studies have been carried out on this, example is a study by Barr and Hall's (1992) which is similar to a study 
by Harvey, Van Raalte, and Brewer (2002) of tennis players that validates the importance of using mental training, their study researched the effects of mental skills, specifically positive self-talk, on golfers' performances. Three groups of golfers used either positive self-talk, negative self-talk, or no self-talk when golfing. Comparatively, the study found that the group that used negative self-talk performed worse while golfing than did the groups that used no self-talk or positive self-talk, but when too much positive self-talk was used, performance also diminished, this support the findings of this study that mental skill of self-talk have positive effect on table-tennis performance and also increase their confidence. This research is important to athletes and coaches because it proves that thinking negatively can hinder performance, but too much positive self-talk can be detrimental to performance as well. There appears to be a fine line as to how much mental preparation is optimal. Athletes need to experiment using different levels of self-talk to find what suits them best. Just as over or under-training physically can be detrimental, so too can mental training.

Along the same lines, Malouff et al. (2008) researched the effects of tennis players' serving accuracy with various types of mental preparation. Tennis players were split into two groups using self-talk and visualization and a control group. Before each serve, players in the self-talk group were to state some type of self-instruction to themselves. Members of the self-talk group had a list of self-instructions to use as a guide if they chose. Before each serve, players in the visualization group were to imagine the whole serve, imagining how the ball would move, how they would feel, and what the outcome would be. Players in the control group were to serve as they normally would and were not given any instructions on mental preparation. The participants were also given a survey at the end to see how frequently they used the mental skills. The results concluded that both the visualization and self-talk groups achieved equally greater accuracy than the group that didn't use any mental preparation. Research by Malouff et al. (2008) demonstrates that positive mental preparation prior to competition can lead to stronger performances which corroborate the findings of this study that mental skills techniques adopted have positive influence on athletes performance and confidence level. According to research by Van Raalte et al. (1994) and Wrisberg and Anshel (1997), negative thinking and selftalk can be detrimental to an athlete's performance. Wrisberg and Anshel's research looked at the effects of performance reinforcements on the outcome of field-hockey penalty shots by splitting the athletes into groups using positively worded reinforcements, negatively worded reinforcements, and a control group. One example of negative reinforcement for distance runners could be, "Don't false start." An example of a positive reinforcement could be, "Watch for the smoke of the gun." Negative reinforcement is when athletes tell themselves not to do something, while positive reinforcement is instructional but in a positive light. Van Raalte et al. (1994) studied tennis players during competition and found that tennis players who were winning both set goals, used positive self-talk and believed in all these techniques. Similarly, Hardy, Jones, and Gould (as cited in Hamilton, Scott, and MacDougall 2007) looked at why mental training was beneficial to athletes. They found that the performance of athletes who used positive self-talk improved because it brought on a higher level of confidence and helped control anxiety levels. Mental preparation is important for many athletes as found with tennis players (Malouff et al. 2008; Van Raalte et al. 1994), golfers (Harvey, Van Raalte, and Brewer 2002), field hockey players (Wrisberg \& Anshel 1997), and rowers (Barr \& Hall 1992). Positive thinking is an important way to keep anxiety, panicking, and choking to a minimum.

Hamilton, Scott, and MacDougall (2007) studied the effects of self-talk with endurance bicyclists. They found that a majority of riders performed best with either assisted or self-regulated positive self-talk. However, they unexpectedly found that a few bicyclists performed better when negative self-talk was used. Therefore, it is imperative for athletes and coaches to experiment and build upon mental training strategies like goal-setting, imagery, self-talk, visualization etc to boost their confidence level in other to attain peak performance of excellence.

\section{Conclusion and Recommendations}

The findings of the present study show support for the positive effect of mental-skills training such as goal-setting, self-talk, visualization and confidence on table-tennis players' performance. The results also showed the importance of mental-skill techniques in practice and competition as well. It is recommended that incorporating of mental-skills techniques into training and competitions can be beneficial to the athletes and the coaches in the attainment of excellent performance. Coaches have the skills, knowledge, and experience to guide their athletes through the physical and technical preparation, the athlete should take responsibility for their own mental-skills use through proper consultation of a trained sport psychologist.

\section{References}

[1]. Barr, K. A., and C. R. Hall. 1992. The use of imagery by rowers. International Journal of Sport Psychology 23(3):243-261.

[2]. Beilock, S. L., Afremow, J. A., Rabe, A. L., \& Carr, T. H. (2001). 'Don't Miss!' The debilitating effects of suppressive imagery on gulf putting performance. Journal of Sport \& Exercise Psychology, 23(3), 200-221.

[3]. Frey, M. M., Laguna, P. L., \& Ravizza, K. K. (2003). Collegiate athletes' mental skill use and perceptions of success: an exploration of the practice and competition settings. Journal of Applied Sport Psychology, 15(2), 115-128. 
[4]. Gould, D., Udry, E., Tuffey, S., \& Loehr, J. (1996). Burnout in competitive junior tennis players: I. A quantitative psychological assessment. The Sports Psychologist, 10, 322-340

[5]. Hamilton, R. A., D. Scott, and M. P. MacDougall. (2007). Assessing the effectiveness of self-talk interventions on endurance performance. Journal of Applied Sport Psychology 19(2):226-239.

[6]. Harvey, D. T., J. Van Raalte, \& B. W. Brewer (2002). Relationship between self-talk and golf performance. International Sports Journal (6):84-91.

[7]. Jacobs, A. (1991). The winning edge in sports [Video file]. Available from http://digital.films.com/play/UWNRLW

[8]. Kelly, S. (2012). Effects of mental-skills training on collegiate divers' performance and perception of success. University of NewYork

[9]. Malouff, J. M., J. A. McGee, H. T. Halford, \& S. E. Rooke.(2008). Effects of precompetition positive imagery and self-instructions on accuracy of serving in tennis. Journal of Sport Behavior 31(3):264-275.

[10]. Mamassis, G., \& Doganis, G. (2004). The effects of a mental training program on juniors precompetitive anxiety, self-confidence, and tennis performance. Journal of Applied Sport Psychology, 16, 118-137.

[11]. Van Raalte, J. L., B. W. Brewer, P. M. Rivera, and A. J. Petitpas. (1994). The relationship between observable self-talk and competitive junior tennis players' match performances. Journal of Sport \& Exercise Psychology 16(4):400-415.

[12]. Myers, N. D., Payment, C. A., \& Feltz, D. L. (2004). Reciprocal relationships between collective efficacy and team performance in women's ice hockey. Group Dynamics: Theory, Research, and Practice, 8(3), 182-195.

[13]. Orlick, T., \& Partington, J. (1988). Mental links to excellence. Sport Psychologist, 2(2), 105-130.

[14]. Passer, M. W. (1983). Fear of failure, fear of evaluation, perceived competence, and self-esteem in competitive-trait-anxious children. Journal of Sport Psychology, 5(2), 182-188.

[15]. Papacharisis, V., Goudas, M., Danish, S. J., \& Theodorakis, Y. (2005). The effectiveness of teaching a life skills program in a sport context. Journal of Applied Sport Psychology, 17(3), 247-254. Doi: 10.1080/10413200591010139

[16]. Scanlan, T. K., Stein, G. L., \& Ravizza, K. (1989). An in-depth study of former elite figure skaters: II. Sources of enjoyment. Journal of Sport \& Exercise Psychology, 11, 65-83.

[17]. Sullivan, P. A. (1993). Communication skills training for interactive sports. Sport Psychologist, 7(1), 79-91.

[18]. Thomas, P. R., Murphy, S. M. and Hardy, L. (1999) Test of performance strategies: Development and preliminary validation of a comprehensive measure of athletes' psychological skills. Journal of Sports Sciences, 17(9), 697-711. Doi: $10.1080 / 026404199365560$

[19]. Wiese, D. M., \& Weiss, M. R. (1987). Psychological rehabilitation and physical injury: Implications for the sports medicine team. Sport Psychologist, 1(4), 318-330.

[20]. Wrisberg, C. A., \& M. H. Anshel. 1997. The use of positively worded performance reminders to reduce warm-up decrement in the field hockey penalty shot. Journal of Applied Sport Psychology 9(2):229-240.

[21]. Yukelson, D. D. (1997). Principles of effective team building interventions in sport: A direct services approach at Penn State University. Journal of Applied Sport Psychology, 9(1), 73-96. 